\title{
Rheumatic heart disease and M680I mutation in two atypical FMF patients: More than an incidental coexistence?
}

\author{
Fatma Gul Yurdakul*, Asli Caliskan Uckun and Hatice Bodur \\ Department of Physical Medicine and Rehabilitation, Ankara Numune Education and Research Hospital, Ankara, Turkey
}

\begin{abstract}
Familial Mediterranean Fever (FMF), the most prevalent monogenic autoinflammatory syndrome, is featured by repetitive episodes of fever and serosal inflammation. We report two cases. Both cases had been followed up for years with ankylosing spondylitis (AS). Despite ideal medical management for AS, clinical and laboratory improvement had not been achieved. Both of the cases had rheumatic heart disease (RHD), a heterozygous mutation for M680I in the MEFV gene, high serum amyloid A (SAA), negative HLA B27 and increased proteinuria levels. With the re-evaluation of the patients, they were diagnosed with incomplete FMF. Significant improvement was detected in both patients with colchicine treatment. It should be kept in mind that we may encounter many atypical presentations of FMF. And these atypical presentations can lead to delayed diagnosis and life-threatening problems such as amyloidosis. We also consider that M680I gene mutation may cause a tendency to the RHD; maybe this coexistence in our patients is only incidental.
\end{abstract}

\section{Introduction}

Familial Mediterranean Fever (FMF), the most prevalent monogenic autoinflammatory syndrome, is featured by repetitive episodes of fever and serosal inflammation. FMF is recognized as an autosomal recessive hereditary disease, associated with a gene named MEFV [1].

FMF can be separated into 2 phenotypes as "typical" and "atypical" forms. An atypical attack is distinguished from typical attack in 1 or 2 characteristics (no fever or lower than $38^{\circ} \mathrm{C}$; shorter or longer duration of the attack; no symptoms of peritonitis; localized abdominal attacks; arthritis of unexpected joints) $[2,3]$.

Acute rheumatic fever (ARF) is an immune-mediated disease resulting from group A $\beta$-hemolytic streptococcal pharyngitis. Remarkable higher prevalence of mutated allele frequency for the MEFV gene in ARF patients compared to healthy individuals was found [4].

In this paper, we will report two cases. The first case had rheumatic heart disease (RHD) and FMF. Case 2 had RHD and FMF spondylitis. Both of the cases had been followed up for years with ankylosing spondylitis (AS), had a heterozygous mutation for M680I in the MEFV gene, high serum amyloid A (SAA) and increased proteinuria levels. We want to emphasize that the symptoms of FMF may be atypical and it may cause delayed diagnosis and life-threatening problems such as amyloidosis. Maybe only incidental coexisting RHD and FMF; but we also consider that M680I gene mutation may cause a tendency to the carditis in ARF patients.

\section{Case reports}

\section{Case 1}

A forty-eight-year-old woman was admitted to our outpatient clinic because of widespread pain and right knee swelling. She was diagnosed with ARF at the age of 19 and RHD that resulted in mitral valve replacement (2004). She had a family history of psoriasis and FMF.

She has experienced irregular recurrent knee arthritis, fatigue, sore throat episodes without fever that resolve spontaneously in 24-72 hours. The attacks have appeared once in every 1-3 months. From 2012 to 2016 she received several treatments (salazopyrin, methotrexate, adalimumab, golimumab, infliximab, certolizumab, etanercept) with the diagnosis of spondylarthrtitis (SpA) at different hospitals, but no clinical or laboratory response was obtained with these treatments.

Physical examination revealed tenderness and swelling in the left knee. Spinal mobility; Schober's test and chest expansion were normal. Rheumatoid factor, anti-cyclic citrullinated peptide antibodies, antinuclear antibodies and human leucocyte antigen B27 (HLA-B27) were negative. Erythrocyte sedimentation rate (ESR) was $29 \mathrm{~mm} / \mathrm{h}, \mathrm{C}$ reactive protein (CRP) $12 \mathrm{mg} / \mathrm{dl}$ (normal range $0-5 \mathrm{mg} / \mathrm{dl}$ ), and antistreptolysin $\mathrm{O}$ (ASO) concentration $57 \mathrm{IU} / \mathrm{ml}$ (normal range 0-200 IU/ $\mathrm{ml}$ ). Genetic analysis confirmed a heterozygous mutation for M680I in the MEFV gene. Proteinuria was detected in 24-hour urine collection. SAA level was $1.65 \mathrm{mg} / \mathrm{dl}$ (normal range $<0.64 \mathrm{mg} / \mathrm{dl}$ ). There were no abnormal findings of the sacroiliac joint and lumbar spine for SpA.

Although she was previously diagnosed and treated as SpA, we considered that her findings were incompatible with this diagnosis and

${ }^{\star}$ Correspondence to: Fatma Gul Yurdakul, MD, Department of Physical Medicine and Rehabilitation, Ankara Numune Education and Research Hospital, Ankara, Turkey, E-mail: fatmagulonder@gmail.com

Key words: Rheumatic heart disease, Familial Mediterranean Fever, MEFV

Received: September 10, 2018; Accepted: September 19, 2018; Published: September 21, 2018 
she has not met ASAS (Assessment of SpondyloArthritis international Society) criteria [5].

She met diagnostic criteria for incomplete form of FMF [2]. She received colchicum $0.5 \mathrm{mg}$ three times daily. Her complaints (pain and knee swelling) noticeably decreased. Acute phase reactors (AFR), proteinuria in 24-h urine and SAA were found to be normal.

\section{Case 2}

A forty-six-year-old woman was admitted to our outpatient clinic with complaints of inflammatory low back pain, widespread myalgia and knee arthritis episodes without fever that resolve spontaneously in 3-5 days. She was diagnosed with AS at age 43. Her medical history revealed mitral valve replacement at 30 years of age due to rheumatic fever at 14 years of age. She had a family history of FMF. On physical examination, she has not peripheral arthritis. Lumbar spinal motion was minimally limited. Sacroiliac provocation tests were positive. Chest expansion was normal. Her laboratory exam showed CRP 26 $\mathrm{mg} / \mathrm{L}$; ESR $22 \mathrm{~mm} / \mathrm{h}$. HLA B27 was negative. SAA was $3.02 \mathrm{mg} / \mathrm{dl}$. Urine examination showed proteinuria. Genetic analysis confirmed a heterozygous mutation for M680I in the MEFV gene. X-rays indicated squaring of the lumbar vertebrae, and bilateral grade 2 sacroiliitis (Figures 1 and 2). She met diagnostic criteria for incomplete form of FMF [2]. She also met the criteria of ASAS [5]. We considered that it may be FMF spondylitis rather than the coexistence of AS and FMF. She received colchicum $0.5 \mathrm{mg}$ three times daily. AFR, proteinuria and SAA were found to be normal.

\section{Discussion}

Both of our cases presented had M680I heterozygous mutation, carditis due to acute rheumatic fever and high SAA levels, proteinuria and had been followed up as AS for a long time. We aim to emphasize that delayed diagnosis due to atypical symptoms leads to untreated or insufficiently treated patients who carry the risk of amyloidosis, which is an important reason for life-threatening organ failure. Also, the coexistence of the same MEFV mutation (M680I) and RHD in both of our patients can be considerable.

FMF patients were noticed to tend to the viral infection and complications of streptococcal infections. Carrying only one heterozygous MEFV mutation was shown to be caused immune hyperactivity against streptococcal antigens, so that these patients may have a tendency to ARF and RHD [4,6]. MEFV gene has been analyzed

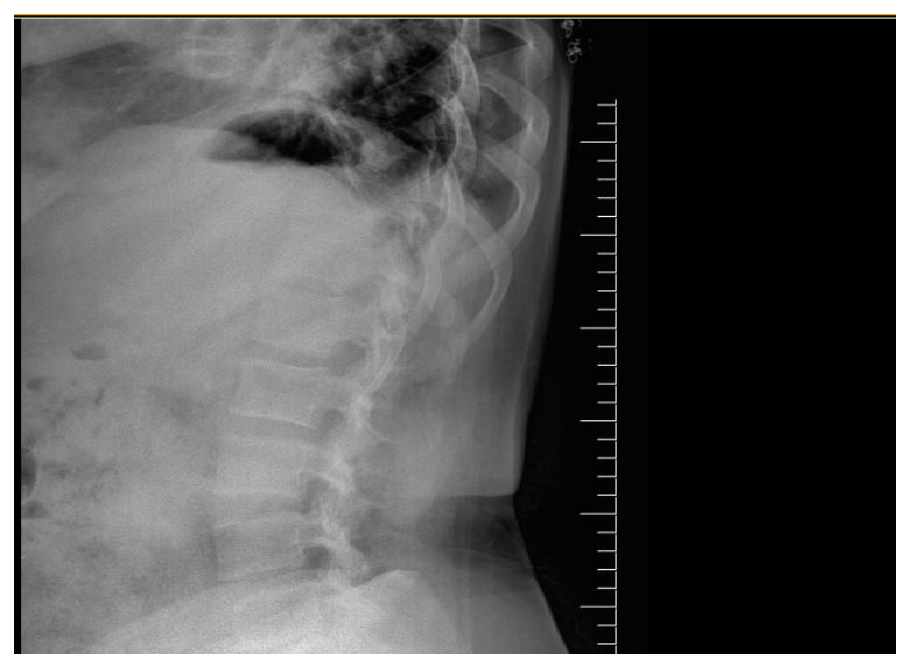

Figure 1. Squaring of the lumbar vertebrae

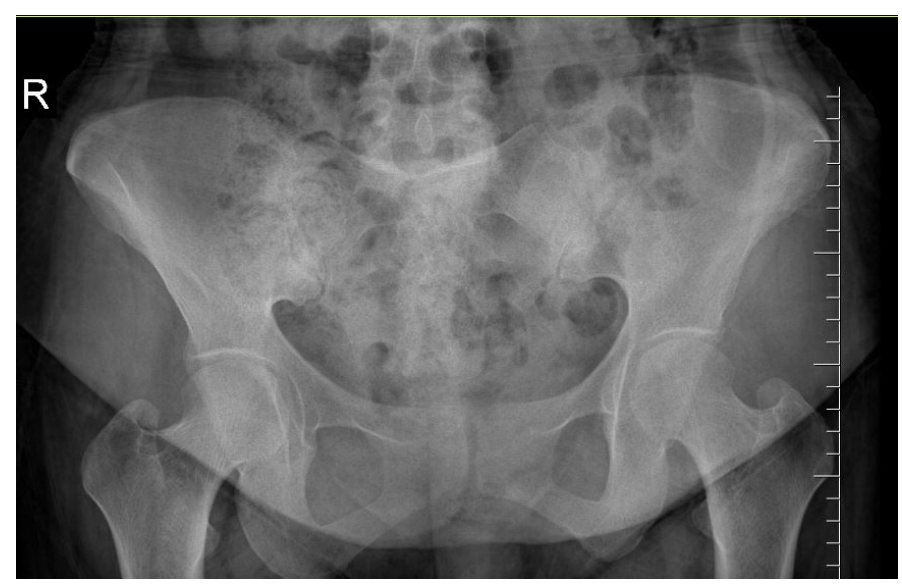

Figure 2. Sacroiliac joint radiography of the patient demonstrating bilateral sacroiliitis

in RHD patients in some studies which had different results [6,7]. While Simsek et al did not find any significant relationship between MEFV gene mutation and RHD, Tutar et al discovered that almost four times more MEFV mutation prevalence in patients with RHD than in the normal population [6,7]. But the main point is that the main mutation (MEFV 680I) in the RHD patients (4 of 6 patients) seen in the Tutar' study is the same in ours. Perhaps the most important MEVF mutation for RHD development may be M680I.

Secondary amyloidosis, primary protein is AA, is a kind of amyloidosis found together with chronic inflammatory diseases. Certain therapeutic regimen is not available, and the most ideal option is to cure the underlying condition and so to reduce acute inflammatory reaction [8]. Identifying FMF as early as possible is very important for preventing amyloidosis and associated renal failure. Keles and friends found that the percentage of FMF patients in renal transplant waiting list was $8.4 \%$. In our patients, FMF was misdiagnosed because of atypical symptoms [9]. Both cases had increased the amount of 24hour urine protein and SAA. After the initiation of colchicine therapy with FMF diagnosis, the patients' results were improved.

Researchers have shown that the incidence of sacroiliitis increases in FMF patients. HLA-B 27 is often negative in FMF patients with sacroiliitis. Case 2 met both the criteria for incomplete form of FMF and sponyloarthropathy based upon the ASAS criteria. When FMF spondylitis is compared with other spondyloarthropathies, FMF spondylitis do not contain uveitis, involvement of anterior chest wall, or important changes in spinal radiology [10]. We thought that she had FMF spondylitis rather than the coexistence FMF and AS.

It should be remembered that FMF, which is common in our country, may begin with atypical clinical presentations. Identification of atypical FMF may keep a major role to prevent life-threatening complications such as renal failure. Also, we consider that the relationship between M680I mutation and rheumatoid carditis should be investigated.

\section{References}

1. Ben-Chetrit E, Levy M (1998) Familial Mediterranean fever. Lancet 351: 1658-1659.

2. Livneh A, Langevitz P, Zemer D, Zaks N, Kees S, et al. (1997) Criteria for the diagnosis of familial Mediterranean fever. Arthritis Rheum 40: 1879-1885. [Crossref]

3. Kosan C (2003) Diagnostic Aproach to Familial Mediterranean Fever. Eurasian J Med 35: 1-6.

4. Nalbantoglu S, Dogrusoz B, Levent E, Ozyurek R, Berdeli A (2016) Significant Association of Mediterranean Fever Gene Mutations with Acute Rheumatic Fever. Int J Autoimmune Disord Ther 2: 107. 
5. Rudwaleit M, van der Heijde D, Landewe R, Listing J, Akkoc N, et al. (2009) The development of Assessment of SpondyloArthritis international Society classification criteria for axial spondyloarthritis (part II): validation and final selection. Ann Rheum Dis 68: 777-783. [Crossref]

6. Tutar E, Akar N, Atalay S, Yilmaz E, Akar E, et al. (2002) Familial Mediterranean fever gene (MEFV) mutations in patients with rheumatic heart disease. Heart 87: 568-569. [Crossref]

7. Simsek I, Koz C, Basar N, Sari I, Erdem H, et al. (2011) Mediterranean fever (MEFV) gene mutation frequency is not increased in adults with rheumatic heart disease. Clin Rheumatol 30: 491-495. [Crossref]
8. Gottenberg JE, Merle-Vincent F, Bentaberry F, Allanore Y, Berenbaum F, et al. (2003) Anti-Tumor Necrosis Factor Therapy in Fifteen Patients with AA Amyloidosis Secondary to Inflammatory Arthritides. A Follow-up Report of Tolerability and Efficacy. Arthritis \& Rheumatism 48: 2019-2024. [Crossref]

9. Keles M, Eyerci N, Uyanık A, Aydinli B, Sahin GZ, et al. (2010) The frequency of familial mediterranean Fever related amyloidosis in renal waiting list for transplantation. Eurasian J Med 42: 19-20. [Crossref]

10. Sarı I, Birlik M, Kasifoglu T (2014) Familial Mediterranean fever: An updated review. Eur J Rheumatol 1: 21-33. [Crossref]

Copyright: @2018 Yurdakul FG. This is an open-access article distributed under the terms of the Creative Commons Attribution License, which permits unrestricted use, distribution, and reproduction in any medium, provided the original author and source are credited. 